\title{
QUALIDADE EM EDUCAÇÃO: CONTRIBUTO PARA UMA HERMENÊUTICA DO CONCEITO
}

\author{
Maria Laurinda Martins Pires Sanches* \\ Nuno Filipe Rosa Melão**
}

Resumo: Reconhecido o fracasso da universalização do acesso à Educação, na promoção da igualdade de oportunidades, assiste-se à mudança do paradigma quantitativo para o paradigma qualitativo. Esta mudança parece enquadrar-se num movimento mais amplo que afeta o Estado, na generalidade dos países. Este artigo propõe um itinerário possível para uma hermenêutica do conceito de Qualidade em Educação, no contexto de mudança vivido neste início do Século XXI. Para o efeito, são mobilizadas diversas abordagens, nomeadamente, a sociológica, a económica, a política e a da investigação educacional. O modelo conceptual, resultante das várias perspetivas, traduz a complexidade e a polissemia do conceito.

Palavras-chave: Qualidade, qualidade educativa, avaliação, educação para todos, escola inclusiva.

\begin{abstract}
Once the failure of the universal access to education was recognized, in the promotion of equal opportunities, we are witnessing a shift from the quantitative paradigm to the qualitative paradigm. This change seems to fit a broader movement that affects the State, in most countries. This paper proposes a possible route for a hermeneutics of the concept of Quality in Education in the context of change experienced at the beginning of the XXI Century. To this end, several approaches are mobilized, in particular, the sociological, the economical, the political, and the educational research perspectives. The conceptual model, resulting from the various perspectives, reflects the complexity and the polysemy of the concept.
\end{abstract}

Keywords: Quality, quality of education, evaluation, education for all, inclusive school.

\footnotetext{
Mestre em Ciências da Educação, Centro Regional das Beiras, Universidade Católica Portuguesa. E-mail: marialaurindasanches@gmail.com

** Docente do Centro Regional das Beiras, Universidade Católica Portuguesa. E-mail: nmelao@crb.ucp.pt
} 


\section{INTRODUÇÃO}

Desde finais da década de 70 do séc. XX, o avanço do neoliberalismo, favorecido pelo falhanço de um Estado-Providência hiperbolizado em serviços nem sempre eficazes, trouxe alterações significativas de paradigmas, na forma como são perspetivados o Estado e os serviços por ele prestados, nomeadamente o serviço público de Educação. O Estado, agora regulador/avaliador, restringe a sua abrangência, descentralizando e delegando competências nas comunidades locais e no setor privado, numa lógica de democracia participada. As Administrações Públicas têm vindo a balançar entre estas "correntes participativas" que defendem o envolvimento e a participação ativa dos cidadãos e as "correntes gestionárias", inspiradas no setor privado, que preconizam a orientação para os resultados (Carapeto \& Fonseca, 2006).

A atual crise económica e financeira, à escala global, veio agudizar a necessidade de racionalização da gestão pública. Conceitos como a qualidade, a eficiência e a eficácia são introduzidos no setor público e são importadas práticas do setor empresarial. As mudanças que assolam a Escola inserem-se neste movimento, embora com algumas componentes específicas que a distinguem do restante setor público, conferindo uma complexidade acrescida ao conceito de Qualidade Educativa.

Mas, o que se entende por Qualidade Educativa? As teorias que servem de lente para interpretar a realidade nem sempre coincidem nas suas focalizações. Haverá coerência entre as diversas interpretações do conceito de Qualidade em Educação? O presente artigo pretende revisitar abordagens colhidas na revisão de literatura. Salientamos que autores como Afonso (1998), Bolívar (2003), Carapeto e Fonseca (2006), Diaz (2003), Hanushek (2005), Lima (2008), Marchesi e Martín (1998) e Morgado (2004), bem como diversas publicações de organizações internacionais (Eurydice, OCDE, UNESCO) constituem os pontos de partida e os guias da nossa reflexão.

\section{QUALIDADE: UM IMPERATIVO ATUAL NA EDUCAÇÃO}

\subsection{A meta da universalidade da Educação}

No Pós-Segunda Guerra Mundial, nos designados "Trinta Anos Gloriosos", passa a vigorar a tese de que o investimento em Educação é sinónimo de crescimento económico. Nesta lógica, assiste-se um pouco por todo o mundo ao incremento exponencial do investimento público em Educação (Marchesi \& Martín, 1998; Hanushek, 2005).

Numa perspetiva microeconómica e numa situação de crescimento económico, tem sido verdadeira a correlação positiva entre nível de 
formação e rendimento do trabalho. Dito de outro modo, estudar compensa, em termos individuais, pelo acesso a tarefas ou cargos substancialmente melhor remunerados (OCDE, 2008a; OCDE, 2009a). Portugal situa-se no grupo dos países que apresentam discrepâncias mais significativas entre remunerações do trabalho, consoante o nível de estudos alcançado (OCDE, 2009b).

Os dados recolhidos traduzem o aumento da procura de Educação nos países da OCDE, de certa forma, ultrapassando as expectativas (OCDE, 2008b; 2009b). Contudo, importa salientar que a expansão não se operou uniformemente (OCDE, 2009b).

Além do aspeto económico, Hanushek (2005) refere as implicações positivas do alargamento da Educação no próprio desenvolvimento social; pois indivíduos mais escolarizados são cidadãos mais reflexivos e mais ativos, política e socialmente. Os estudos da OCDE (2009b) vão ao encontro desta ideia, concluindo que existe uma correlação positiva entre o nível de qualificação e a postura do indivíduo perante itens como a saúde, a participação cívica e política e a forma como encara a própria vida (maior ou menor otimismo, integração social e sentimento ético). Ou seja, a Educação também contribui para a coesão e o desenvolvimento social (OCDE, 2009b)

A conjuntura atual de crise económica poderia fazer esperar um decréscimo da procura de Educação. Contudo, perante a agudização das dificuldades, na conquista do primeiro posto de trabalho, "a expansão continua" (OCDE, 2009c, p.2), embora com discrepâncias entre os diversos países.

\subsection{Do paradigma quantitativo ao paradigma qualitativo}

Os constrangimentos financeiros da década de 70 abriram caminho para o advento do neoliberalismo que sustentou ideologicamente as mudanças ocorridas nas administrações públicas ao longo das últimas décadas. A crise económica atual, conjugada com este movimento neoliberal, veio abalar a lógica do paradigma quantitativo e trouxe, sobretudo, a urgência de um olhar mais racional na gestão da coisa pública (Afonso, 1998; Carapeto \& Fonseca, 2006).

O triunfo do paradigma qualitativo, no setor da Educação, insere-se portanto neste contexto. Ou seja, não basta proporcionar o acesso a todos os indivíduos, sob o lema da igualdade de oportunidades. Importa agora assegurar a igualdade de oportunidades no sucesso, quer em termos individuais, quer com garantia de mais-valias em termos económicos e sociais, ou seja, conteúdos pertinentes. A aposta na melhoria da Qualidade Educativa, em sentido lato, torna-se vital (Afonso 1998; 
Carneiro, 2004; Morgado, 2004; Hanushek, 2005, OCDE, 2008a, 2008b, 2009a, 2009b).

Alguns autores têm posto em causa a premissa mais investimentos/melhor educação. Neste âmbito, Hanushek (2005) não hesita em afirmar "Aunque la educación estimula el crecimiento económico, simplemente gastar más es rara vez la solución" (p.15). Aliás, como explica o autor, o valor acrescentado, para investimentos idênticos, é substancialmente maior em países subdesenvolvidos do que em países que já têm infraestruturas consolidadas.

No âmbito da educação formal, a componente não cognitiva constitui uma parte significativa das metas educativas. Por outro lado, sendo os reflexos do ato educativo dilatados no tempo, os seus efeitos apenas se tornam visíveis nas gerações vindouras. Surgem múltiplas interrogações. Que critérios presidem à decisão sobre os conhecimentos considerados relevantes e passíveis de ser avaliados? Por que razão alguns indivíduos alcançam aquisições e outros, não? Quais são os instrumentos pertinentes e adequados para avaliar?

Colocamo-nos, pois, em concordância com Hanushek (2005) quando sublinha "la "cantidad" de educación es un indicador muy aproximado de los conocimientos e de las aptitudes de las personas" (p.16).

Existe literatura abundante sobre a temática e o discurso político, ancorado nas estatísticas e materializado nos normativos, também é profícuo em referências à melhoria da qualidade. $\mathrm{O}$ art. ${ }^{\circ} 3^{\circ}$ da Lei 31/2002 de 20 de dezembro (Sistema de Avaliação da Educação e do Sistema de Ensino Não Superior), estabelece, entre outros, os seguintes objetivos:

a ) Promover a melhoria da qualidade do sistema educativo, da sua organização e dos seus níveis de eficiência e eficácia ...

c) Assegurar o sucesso educativo, promovendo uma cultura de qualidade ...

d) Permitir e incentivar as ações e os processos de melhoria de qualidade ...

O debate em torno da questão da Qualidade da Educação não é novo, nem é problema exclusivo do nosso país. A maioria dos países desenvolvidos orienta agora os seus esforços para esta vertente (Marchesi e Martín, 1998; Eurydice, 2007a, 2007b).

\subsection{Qualidade Educativa: um conceito subjetivo e polissémico}

Por muita pesquisa que tenhamos feito, não conseguimos encontrar uma definição consensual para o conceito de Qualidade e, muito menos, para Qualidade Educativa. Nesta linha de pensamento, encontrámos 
várias referências (Marchesi e Martín, 1998; OCDE, 1992; Diaz, 2003; Ankomah et al., 2005; Lima, 2008; Esteban 2008). O conceito de Qualidade em Educação é pois altamente subjetivo e relativo porque é refém do ângulo de análise, o que lhe confere um estatuto polissémico e, por isso mesmo, complexo. Reconhece a Escola essa pluralidade de sentidos? Esteban (2008) não hesita em expressar as suas dúvidas: a Escola assenta num modelo que define códigos e padrões culturais uniformes, considerando valiosas determinadas culturas em detrimento de outras.

Conscientes da diversidade de olhares, umas vezes opostos, outras vezes complementares, encontrámos, na revisão de literatura, algumas linhas mestras que nos ajudaram a compreender melhor os dilemas que afetam atualmente a Educação.

\section{A QUALIDADE EDUCATIVA EM PERSPETIVA}

O fenómeno da globalização, impulsionado pelo avanço das Tecnologias de Informação e Comunicação (TIC), favoreceu um movimento de mudança, a nível mundial, contribuindo para esbater fronteiras, abalar valores instituídos e redefinir territórios económicos e sociais. Constata-se uma tendência da comunidade internacional em unir esforços e uniformizar políticas, em diversos domínios. Pretendemos, por isso, deter-nos brevemente no esforço que os diversos países têm dedicado à temática da Qualidade em Educação.

A seguir, propomos um itinerário possível pela temática da Qualidade Educativa, cientes que a análise não se esgota aqui, dada a imensa complexidade da matéria.

\subsection{As finalidades da Educação: uma questão central}

A ideia que se tem sobre as finalidades da escola é, na verdade, uma questão central. O princípio da Educação para Todos ou Escola Inclusiva surge na lógica da defesa da equidade social. A Educação tem de contribuir para garantir uma maior equidade, o que implica garantir que todos tenham condições para obter sucesso educativo, sabendo que os alunos chegam em condições desiguais, à escola. $\mathrm{O}$ enfoque do conceito de Qualidade Educativa, na atualidade, situa-se neste paradigma. Ou seja, não basta atingir taxas universais de inscrição e muito menos de certificação. As aquisições realizadas na Escola, nos domínios cognitivo e não cognitivo, têm de ter implicações reais.

Para alguns autores (e.g., Barrett et al., 2006), a Educação visa desenvolver determinadas características consideradas desejáveis ou boas, embora sem consenso quanto ao conceito de desejável ou bom. A 
representação do conceito de Qualidade Educativa implica necessariamente uma hierarquia de valores de ordem ideológica e política, quanto ao ideal de sociedade. Algumas abordagens acentuam, assim, o papel da Educação na formação do indivíduo e no desenvolvimento das suas capacidades, enquanto outras enfatizam a dimensão económica e social dos seus efeitos.

No caso Português, a Lei de Bases do Sistema Educativo, de pendor marcadamente humanista, atribui ao sistema educativo um papel instrumental na concretização do direito à Educação, devendo "favorecer o desenvolvimento global da personalidade, o progresso social e a democratização da sociedade" (art. $\left.{ }^{\circ} 1^{\circ}\right)$. Dos princípios gerais enunciados no art. $^{\circ} 2^{\circ}$, destacam-se, por exemplo, a promoção da "democratização do ensino" e "o direito a uma justa e efetiva igualdade de oportunidades no acesso e sucesso escolares". Na missão do sistema educativo, são consagrados valores como a resposta às "necessidades da realidade social", "o desenvolvimento pleno e harmonioso da personalidade", "a formação de cidadãos livres, responsáveis, autónomos e solidários" e a "valorização da dimensão humana do trabalho".

$\mathrm{O}$ caso da Educação é complexo porque, sendo um instrumento privilegiado para a construção de um ideal de sociedade, ao dispor do poder político, é simultaneamente o resultado dessas mesmas opções políticas.

\subsection{O peso da ideologia política}

Balanceado entre uma abordagem democrática da Escola, associada ao chavão Educação para Todos, e uma perspetiva de cariz neoliberal que promove a competitividade, o conceito de Qualidade transportado para o contexto educativo torna-se indissociável da opção política (Libório, 2004).

A questão de fundo reside na opção por um Estado mais ou menos intervencionista (Marchesi e Martín, 1998). Os autores distinguem, neste âmbito, três ideologias políticas (liberal, igualitarista e pluralista). Num extremo, a ideologia liberal defende um Estado reduzido. A Educação, considerada bem individual, deve predominantemente ser assegurada pela iniciativa privada. As escolas são colocadas numa situação concorrencial relativamente ao produto (Educação), face aos clientes internos e externos. Inserem-se, nesta lógica, princípios como o da livre escolha do estabelecimento pelos pais, a concorrência entre escolas, a disputa pelos melhores alunos, a ênfase nos resultados, o estímulo à competição entre escolas, a prestação de contas, a avaliação de desempenho... No pólo oposto, os autores situam a ideologia igualitarista que preconiza um serviço público de Educação uniforme, única garantia de uma sociedade 
mais justa e coesa. No Quadro 1, apresentamos uma breve resenha das características essenciais das três ideologias.

A política educativa dos últimos 20 anos têm vacilado entre ambos os campos, ora tomando medidas centralizadoras (ideologia igualitarista), ora defendendo a descentralização (ideologias liberal e pluralista).

\section{Quadro I}

Principais características das três abordagens ideológicas da Escola (adaptado de Marchesi e Martín, 1998)

\begin{tabular}{|c|c|c|}
\hline Ideologia & Princípios orientadores & Aspetos relevantes/Consequências \\
\hline Liberal & $\begin{array}{l}\text { - Incentivo à concorrência } \\
\text { entre escolas. Estimula a } \\
\text { melhoria do desempenho, } \\
\text { logo, da qualidade. } \\
\text { - Ênfase nos resultados. } \\
\text { - Livre escolha do } \\
\text { estabelecimento enquanto } \\
\text { instrumento de melhoria da } \\
\text { qualidade. }\end{array}$ & $\begin{array}{l}\text { - Reduzida intervenção do Estado; } \\
\text { - A educação é um produto e os clientes são os } \\
\text { pais e os alunos. } \\
\text { - Melhoria da eficácia (resultados) e da gestão } \\
\text { de recursos (eficiência). } \\
\text { - Ênfase na avaliação baseada nos resultados. } \\
\text { - Escolha das escolas, pelos pais, baseada nos } \\
\text { resultados. Logo, concentração das escolas nos } \\
\text { exames. } \\
\text { - Financiamento das escolas e remuneração } \\
\text { dos docentes em função dos resultados. }\end{array}$ \\
\hline Igualitarista & $\begin{array}{l}\text { - Escolaridade obrigatória } \\
\text { igual para todos os alunos, } \\
\text { enquanto garantia da } \\
\text { igualdade de oportunidades. } \\
\text { - Ênfase na função } \\
\text { igualizadora da Escola e nas } \\
\text { componentes não cognitivas } \\
\text { da Educação. } \\
\text { - Principal missão da } \\
\text { Escola: transmissão e } \\
\text { partilha de uma cultura e de } \\
\text { valores comuns. } \\
\text { - Sistema planeado para } \\
\text { gerar escolas semelhantes, } \\
\text { nos objetivos e nas práticas. }\end{array}$ & $\begin{array}{l}\text { - Liderança da gestão do Sistema e das escolas } \\
\text { a cargo do Estado. } \\
\text { - Reduzida autonomia na gestão dos recursos e } \\
\text { na definição do currículo. } \\
\text { - Desconfiança da descentralização e negação } \\
\text { de projetos educativos próprios. } \\
\text { - Renitência à prestação de contas aos pais. } \\
\text { - Rejeição da livre escolha do estabelecimento } \\
\text { pelos pais assente na livre concorrência entre } \\
\text { escolas. } \\
\text { - Todas as escolas devem ser de qualidade. } \\
\text { Logo, o critério de escolha deve ser o da } \\
\text { proximidade da residência. }\end{array}$ \\
\hline Pluralista & $\begin{array}{l}\text { - Estímulo à confiança num } \\
\text { serviço público de educação } \\
\text { e rejeição da aplicação das } \\
\text { regras do mercado na } \\
\text { Educação. } \\
\text { - Integração de mecanismos } \\
\text { que se crê serem geradores } \\
\text { de melhoria da qualidade. }\end{array}$ & $\begin{array}{l}\text { - Crença num serviço público de educação. } \\
\text { - Crença nos seguintes instrumentos de } \\
\text { melhoria: autonomia das escolas, } \\
\text { descentralização, diversificação da oferta } \\
\text { educativa, avaliação e prestação de contas, } \\
\text { racionalização da gestão. } \\
\text { - Aposta no desenvolvimento dos docentes } \\
\text { assente no trabalho colaborativo e na } \\
\text { satisfação profissional. } \\
\text { - A avaliação interna e externa, enquanto } \\
\text { instrumento de melhoria da qualidade. } \\
\text { - Valorização do conceito de valor } \\
\text { acrescentado pela escola. } \\
\text { - Incentivo às práticas de prestação de contas. } \\
\text { - Escola inclusiva (integração de alunos com } \\
\text { NEE). } \\
\text { - Aceitação da livre escolha dos pais. }\end{array}$ \\
\hline
\end{tabular}


A investigação educacional, ao longo dos últimos 40 anos, tem contribuído significativamente para melhorar a compreensão da Escola. De seguida, propomos um olhar pela trajetória da pesquisa em educação, usando, inicialmente, a lente da Teoria dos Sistemas.

\subsection{Abordagem sistémica da Escola}

Voltamos às finalidades ou efeitos da Escola a que chamaremos resultados (em sentido amplo) ou, numa primeira fase, outputs. Recorrendo à abordagem sistémica da escola, Scheerens (2004) propõe uma conceptualização simples que serve de suporte ao nosso raciocínio (Figura 1). O sistema educativo e as escolas são encarados como sistemas abertos, em constante interação com o meio envolvente (contexto). Recebem inputs e produzem outputs, através de processos de transformação internos que o autor agrupa em dois grandes níveis: a escola e a turma.

Figura 1

Modelo de base do funcionamento da escola inspirado na teoria dos sistemas

(Schreerens, 2004, p.30)

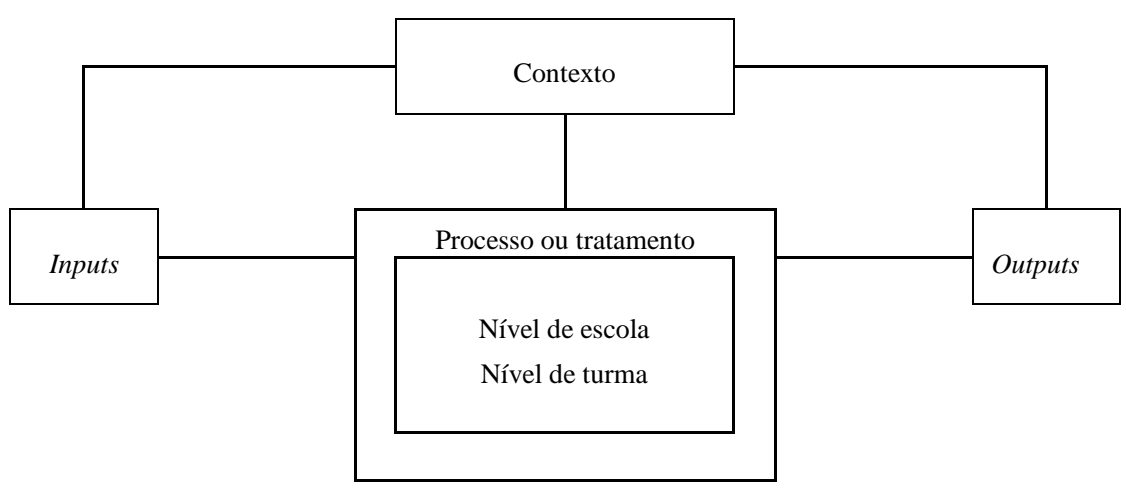

O conceito de finalidades remete para o de objetivos. Parece inconcebível que os Estados despendam montantes tão avultados sem perseguirem objetivos. Nesta linha de pensamento, emerge inevitavelmente o conceito de eficácia, ele próprio complexo e relativo, o que leva Scheerens (2004) a aplicar-se na procura da "nova definição de eficácia da escola" (p.14). Numa primeira fase da sua reflexão, o autor afirma:

Na medida em que a eficácia significa, no sentido literal do termo, a realização de objectivos, é implicitamente aceite que os critérios 
utilizados para medir o desempenho reflictam objectivos educativos fundamentais. (Scheerens, 2004, p.14)

Colocamo-nos em concordância com o autor, pois adotando o prisma da abordagem sistémica da escola, podemos concluir que um sistema educativo ou uma escola são eficazes quando os seus outputs correspondem aos objetivos fixados. A grande dificuldade surge, portanto, na decisão quanto à natureza dos objetivos a fixar e hierarquizar. Diaz (2003) afirma "importa sublinhar que os resultados de uma escola não têm natureza material, [...]; eles são antes constituídos por conceitos tais como capacidades cognitivas e boas atitudes sociais que são exemplos claros do caráter intangível do output educativo" (p.26). Portanto, decidir não é fácil, nem pacífico.

A existência de um currículo nacional traduz-se em disciplinas e programas, como explica Pacheco (2007). O autor atribui a designação de propósitos às finalidades do sistema educativo. $\mathrm{O}$ currículo concretiza, assim, a intencionalidade do ato educativo.

Procurando sintetizar posições convergentes, completamos a análise de Scheerens sugerindo o modelo descrito na Figura 2.

\section{Figura 2}

Abordagem sistémica da Escola - Modelo ampliado (adaptado de Diaz, 2003; Scheerens, 2004; Ankomah et al., 2005)

\section{CONTEXTO}

- Política Educativa e normativos legais

- Famílias e restante comunidade educativa

- Envolvente socioeconómica, meio urbano/rural

- Outros elementos do contexto

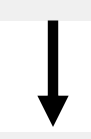

INPUTS

- Características dos alunos

- Características dos profissionais

- Currículo e materiais pedagógicos

- Recursos físicos e equipamentos

- Recursos financeiros

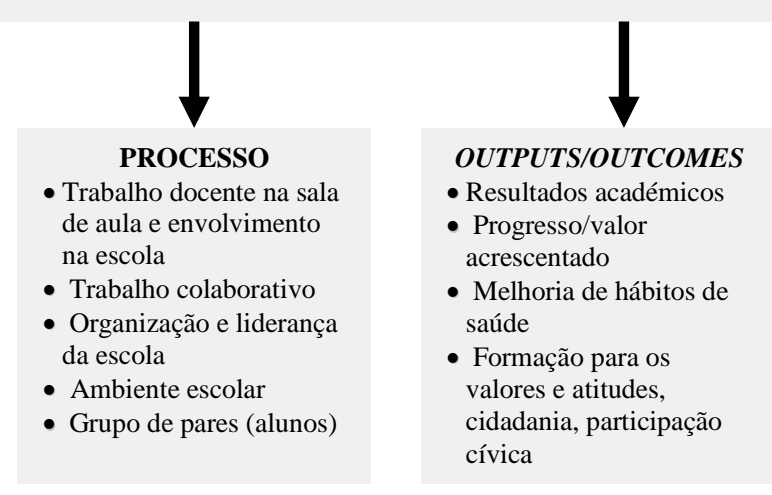

As características dos alunos condicionam os outputs/outcomes e os próprios processos internos. A noção de outcomes, relativamente recente, 
prende-se com resultados não mensuráveis, contrariamente aos outputs (sentido económico). Na Educação, são exemplos de outcomes os valores e atitudes, a aquisição de hábitos de vida saudável ou a formação para a cidadania. A Qualidade Educativa deve, portanto, ser analisada na perspetiva dupla dos outputs e dos outcomes (Ankomah et al., 2005).

Por sua vez, os contextos condicionam os inputs e os processos. Os profissionais, destacando-se os professores, têm uma natureza híbrida. Pois, sendo atores essenciais dos processos, uma parte das suas características é considerada inputs (formação, experiência, estabilidade, remuneração, etc.) (cf. Diaz, 2003; Scheerens, 2004).

Quanto aos processos, revestem-se de uma grande complexidade, em resultado da indeterminação e da natureza complexa da própria organização escolar (cf. Costa, 2003; Diaz, 2003). Diaz (2003) introduz a variável grupo de pares a que o aluno pertence. Embora esta componente seja pouco referida na literatura revisitada, na prática, enquanto profissionais de Educação, conhecemos bem essa importância. $\mathrm{Na}$ maioria dos casos, trata-se de uma variável que foge ao controlo da escola.

Ao abordar os processos, emerge outro conceito importante, o de eficiência. De uma forma simples, enquanto a eficácia resulta da comparação dos resultados obtidos com os expectáveis, a eficiência analisa os recursos utilizados para alcançar os outputs/outcomes desejados. Assim, existe eficiência se o alcance dos resultados é feito da melhor forma, sendo o tempo e os custos, critérios frequentemente utilizados para a sua avaliação. Então, deve procurar-se alcançar os resultados educativos desejados (eficácia), com a melhor eficiência possível. Na verdade, como explica Sheerens (2004), não existe uma única melhor maneira de fazer. Por conseguinte, o conceito de eficiência é, também ele, um conceito relativo.

O aluno entra para a Escola com determinadas características e deve, ou deveria sempre, sair de lá, com outras melhores. Caso contrário, a Escola de nada serviu. Dito de outro modo, a Escola tem de acrescentar valor, tem de garantir progresso; pouco ou muito, mas algum progresso. Contudo, como é sabido, a influência do meio e dos processos que ocorrem fora da Escola é absolutamente decisiva (contexto familiar, educação informal e não formal) (Castillo, 2004).

A abordagem sistémica da Escola serviu-nos de lente para analisar alguns aspetos relevantes da Escola. Outra perspetiva possível, importada do mundo empresarial, é a da orientação para o cliente. Inspirada nos princípios da Qualidade Total, focaliza as atenções na satisfação dos utilizadores do sistema, sejam eles clientes internos ou clientes externos. Neste caso, a Educação tem qualidade se corresponde aos anseios e necessidades de quem serve (UNESCO, 2004). 


\subsection{Abordagens comportamentais vs. abordagens humanistas}

O Relatório da UNESCO (2004) refere-se à centralização enquanto lógica organizativa predominante nos sistemas educativos, o que implica abordagens comportamentais da Escola. A educação é concebida para moldar o comportamento do indivíduo. Em termos pragmáticos, o processo ensino/aprendizagem é balizado pelos parâmetros seguintes:

- uniformidade de programas e objetivos, independentemente das características dos alunos;

- avaliação resultante da medição objetiva das metas alcançadas (prioridade aos testes e aos exames);

- o docente, enquanto elemento nuclear do processo ensino/ aprendizagem.

As abordagens humanistas são colocadas num pólo oposto. O aluno é o centro do processo educativo cujo objetivo principal é o desenvolvimento das potencialidades do indivíduo. Nesta lógica, as consequências práticas são antagónicas, relativamente às abordagens comportamentais, a saber:

- inexistência de programas rígidos e institucionalizados e adequação dos conteúdos às necessidades individuais;

- ênfase na autoavaliação e na avaliação pelos pares;

- o docente, enquanto facilitador da aprendizagem.

Os sistemas educativos vão evoluindo, imbuídos de influências múltiplas e dificilmente encontraremos, hoje em dia, a adoção de uma abordagem única.

\subsection{Os compromissos internacionais: Jomtien e Dakar}

Os sistemas educativos dos países mais desenvolvidos alcançaram grandes conquistas, ligadas à universalidade do acesso, e progressos significativos ao nível da inclusão. Contudo, estes sistemas coabitam, no mundo globalizado, com outros países onde estes princípios básicos se encontram ainda por atingir. Ao longo dos últimos vinte anos, a comunidade internacional tem unido forças, no sentido de esbater as diferenças entre países e regiões e alcançar uma maior equidade social. A linha predominante do pensamento atual sobre o conceito de Qualidade em Educação insere-se no paradigma que temos vindo a discutir, ou seja, igualdade de acesso com iguais oportunidades de sucesso. Educação para Todos é assim o tema aglutinador dos compromissos internacionais alcançados em Jomtien, em 1990, e em Dakar, em 2000. Neste último, 
dos seis objetivos fixados para 2015, destacamos o sexto que propõe apostar na melhoria da qualidade da Educação (UNESCO, 2000).

Em 2002, a UNESCO inicia a publicação de relatórios de acompanhamento da implementação das decisões tomadas em Jomtien e Dakar. O Relatório publicado em 2004 é dedicado ao tema da Qualidade em Educação. O primeiro capítulo sublinha, também ele, a ausência de consenso, quanto à delimitação do conceito de Qualidade Educativa. Todavia, a comunidade internacional converge, unanimemente, quanto à necessidade de: (i) uma maior pertinência dos conteúdos; (ii) uma maior equidade no acesso e nos resultados (sentido amplo); (iii) o respeito pelos direitos individuais (UNESCO, 2004).

Subjacentes ao conceito de Qualidade em Educação existem ideologias, motivações, metas e estratégias diferenciadas. Todas elas, apesar das suas diferenças, perseguem a Qualidade. Perante a diversidade de olhares, o Relatório da UNESCO de 2004 propõe à comunidade internacional um esforço no sentido de encontrar metas e objetivos comuns para a Educação. Assim, identifica dimensões ou fatores que, ao interagirem, determinam a Qualidade Educativa: (i) as características dos alunos; (ii) os contextos externos/meio envolvente; (iii) os fatores contextuais internos da Escola (humanos, materiais, financeiros e organizacionais); (iv) os resultados.

Os paradigmas e dilemas que afetam a sociedade, neste início do século XXI, deslizam naturalmente para a Escola, abalando uma lógica assente na racionalidade e na transmissão de conhecimentos. A instituição escolar é posta em causa, revelando dificuldades de adaptação ao desafio da diversidade cultural, trazida pelo alargamento, dificuldades agudizadas pelo contexto de mudança que a envolve. Para uns, continua a ser o lugar de excelência para a aprendizagem e, enquanto tal, tem que ser um local de ensino. Para outros, é desacreditada e tem que mudar porque o essencial não é aprendido na escola. Nessa medida, a Escola deve preparar o aluno para a aprendizagem ao longo da vida.

De seguida, pretendemos enriquecer o debate com uma breve referência aos resultados da investigação educacional, desenvolvida ao longo das últimas quatro décadas. Damos lugar de destaque a algumas linhas de investigação vocacionadas para a identificação de fatores potenciadores da melhoria da qualidade.

\subsection{Do Relatório Coleman à melhoria eficaz da escola}

A LBSE, no seu art. $^{\circ} 50^{\circ}$, consagra a investigação educacional enquanto pilar da avaliação e do desenvolvimento do sistema educativo, razão que justifica alguma atenção dedicada ao assunto. 
A investigação em educação tomou rumos diversificados, consoante o prisma escolhido na abordagem da problemática do insucesso escolar. Algumas correntes preocuparam-se com o trabalho desenvolvido no espaço sala de aula, a formação de professores, a organização e gestão do currículo ou a administração educacional. Outras correntes ligadas à Sociologia da Educação, privilegiaram um enfoque mais determinista, ao defenderem, basicamente, que os sistemas educativos mantêm e reproduzem a desigualdade social patente na própria sociedade, dando lugar às designadas Teorias da Reprodução. Outras correntes ainda, predominantes nos países anglo-saxónicos (sobretudo, nos EUA e no Reino Unido), orientaram as suas pesquisas em torno das causas da ineficácia dos estabelecimentos de ensino, dando lugar ao Movimento das Escolas Eficazes (Marchesi e Martín, 1998; Morgado, 2004; Lima, 2008).

Neste último campo analítico, a publicação da obra Equality of Educational Opportunity (Coleman et al., 1966) constitui um marco decisivo. Nela, são divulgados os resultados de um estudo desenvolvido pela equipa de investigadores liderada por James Coleman sobre o insucesso dos alunos, sendo o primeiro grande inquérito do género. $\mathrm{Na}$ esteira de Marchesi e Martín (1998), o livro que ficaria conhecido por Relatório Coleman teve um grande impacto social na época. Pois como explicam os autores, a sua publicação surge num período de expansão económica, com grandes investimentos públicos no setor da Educação, na lógica acima descrita: alargamento do acesso/igualdade de oportunidades/alavanca do crescimento. Também teve o seu peso pelo facto de o estudo ter surgido na sociedade americana de então, "profundamente dividida por clivagens económicas e raciais" (Lima, 2008, p.14). O principal objetivo era averiguar a correlação entre a origem social e étnica dos alunos e o seu desempenho na escola. Porém, acabou por permitir também tirar ilações quanto ao peso de fator-escola no (in)sucesso escolar. O Relatório Coleman conclui que a influência da Escola nos resultados dos alunos tem um caráter residual; o que importa verdadeiramente é a origem étnica e socioeconómica dos alunos, razão pela qual se celebrizou a frase que lhe é associada, School makes no difference (Marchesi e Martín, 1998; Lima, 2008). É de registar que as Teorias da Reprodução acima referidas e o Relatório Coleman acabam por convergir na mesma direção, embora sem qualquer vinculação entre eles (Marchesi e Martín, 1998).

Compreende-se que a revelação de tais conclusões tenha gerado grandes perturbações, tanto no campo político como no campo académico. A crença nas potencialidades da Escola em contribuir para a diminuição das desigualdades sociais foi abalada, passando a ser questionados os montantes de fundos públicos aplicados no setor educativo (Lima, 2008, p.18). 
As reações ao ceticismo surgiram com naturalidade, com uma geração de críticos a Coleman e seus seguidores. Salientamos dois pontos emblemáticos das críticas apontadas: (i) o próprio desenho da investigação (metodologia, escolha das variáveis e dos indicadores); (ii) o esquecimento da questão do valor acrescentado pela escola (Marchesi e Martín, 1998; Lima, 2008). Estes autores atribuem aos estudos em causa, o mérito de terem despertado consciências e de terem impulsionado o desenvolvimento da investigação educacional. Trazida para a ribalta a influência do contexto socioeconómico, no desempenho dos alunos, havia que compreender qual é, na realidade, o peso deste fator e qual é o peso da Escola. De facto, permanecia por encontrar a resposta à seguinte questão: por que razão, escolas com populações semelhantes apresentam resultados diferentes? Se não existia uniformidade nos resultados, mesmo em condições de input semelhantes, tinha que haver diferenças entre as escolas. A investigação educacional começou então a orientar a sua pesquisa para o estabelecimento de ensino. Passou a acreditar-se que as escolas divergem, necessariamente, entre elas e que cada uma é única, obedecendo a lógicas de funcionamento próprias que podem fazer toda a diferença. Ou seja, nesta linha de pensamento, constata-se que algumas escolas são mais eficazes do que outras. Ao sustentarem que "os efeitos da escola são mínimos comparados com os do grupo social de origem" (Bolívar, 2003, p.26), Coleman e seus seguidores e os defensores das Teorias da Reprodução haviam condenado os sistemas educativos a um certo determinismo a que se contrapunha agora a crença de que a Escola pode contribuir para a igualdade de oportunidade e que as escolas não são todas iguais (School can make difference). Estava em curso o advento do Movimento das Escolas Eficazes a partir de finais da década de 70, que Lima (2008) divide em duas linhas de investigação: (i) uma, nos EUA, com os trabalhos liderados por Brookover, Edmonds ou Goodlad, em 1979, cujo objetivo era provar que existe de facto um efeitoestabelecimento; (ii) a outra, no Reino Unido, destacando-se nomes como Rutter, em 1979, ou Reynolds, em 1982, preocupados com as diferenças existentes entre escolas e com o peso do sucesso atribuível ao meio ou à escola.

Ao considerar que existem diferenças entre as escolas, a investigação passa a centrar-se no estabelecimento de ensino. $\mathrm{O}$ sistema educativo deixa de ser perspetivado como um conjunto de escolas que registam uniformidade nas suas normas de funcionamento. Esta foi uma premissa essencial porque, até aí, pensava-se que a uniformidade era a garantia da equidade, em nome do princípio da Educação para Todos, muito associado à Escola Pública (Bolívar, 2003).

A prioridade é agora dada à procura dos fatores que influenciam a eficácia da escola, fazendo com que umas sejam mais eficazes do que 
outras. Ao identificar esses fatores e ao definir os respetivos indicadores, pensa-se poder fazer beneficiar os principais atores da escola. A procura da melhoria das escolas é, desde logo, assumida como o grande objetivo das pesquisas realizadas. Foram várias as correntes ideológicas e, decisivos foram, também, os pontos de clivagem, ao longo dos últimos trinta anos. A Figura 3 procura resumir as principais correntes da investigação educacional.

Figura 3

Evolução da investigação educacional (adaptado de Bolívar, 2003)

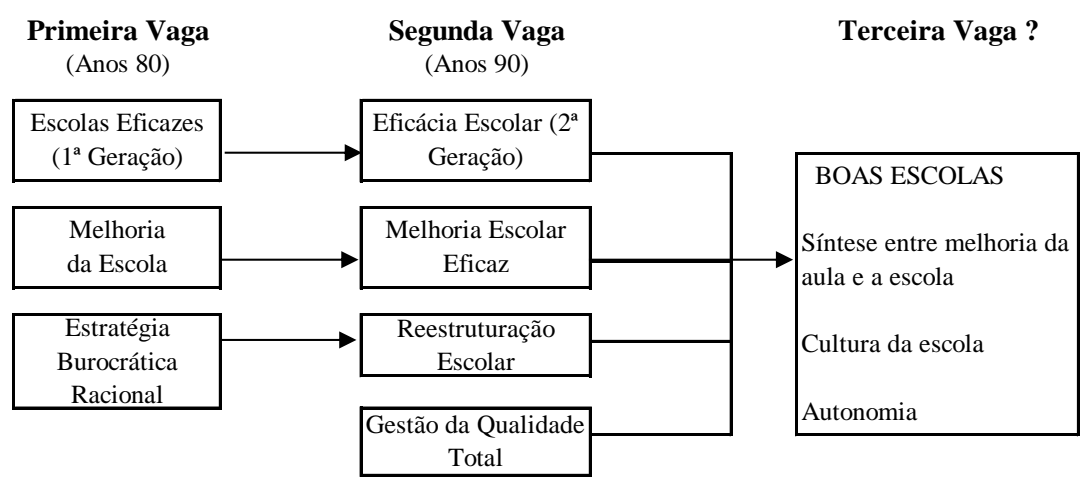

A par do Movimento das Escolas Eficazes, a investigação conta com o contributo de outras correntes, algumas com origem no mundo empresarial e tentativas de decalque, nem sempre bem sucedidos, como por exemplo, a Reestruturação Escolar (Bolívar, 2003). A importação dos princípios da Gestão da Qualidade Total (GQT), ao enfatizar a orientação para os clientes (pais, alunos e sociedade, em geral) contribuiu para colocar as escolas em situação concorrencial (cf. Afonso, 1998) e impulsionou a prestação de contas. Incentiva-se a avaliação das escolas e dos seus profissionais, importam-se modelos organizativos e avaliativos do setor privado, enaltece-se a transparência e procede-se à alteração do campo lexical das escolas. A GQT tem sido usada para sustentar e legitimar a argumentação dos defensores de um mercado de escolas. Os estabelecimentos de ensino lutam pela conquista de alunos, recorrendo ao mecanismo da prestação de contas e da divulgação pública dos resultados da sua avaliação. A publicação dos rankings, ao proceder à ordenação das escolas em função dos resultados obtidos pelos alunos nos exames nacionais, integra esta lógica de prestação de contas, equiparando subrepticiamente a qualidade das escolas ao desempenho na componente 
cognitiva. Ou seja, cai-se outra vez no conceito de eficácia mas limitando a sua abrangência ao item resultados académicos.

Partindo de uma visão pessimista da Escola, na sequência do Relatório Coleman e das Teorias da Reprodução, a investigação educacional, com especial destaque para o Movimentos das Escolas Eficazes e da Melhoria da Escola, aplicou-se em demonstrar que, afinal, a Escola faz diferença ou que pode fazer a diferença. Ou seja, a Escola pode contribuir, em grande medida, para o desenvolvimento do indivíduo e da própria sociedade (Lima, 2008).

\section{AVALIAÇÃO: UM INSTRUMENTO DA QUALIDADE EDUCATIVA}

\subsection{Autonomia, projeto educativo e avaliação}

Seja qual for a atividade e o nível hierárquico, entendemos que a fixação de metas e objetivos exige a implementação de sistemas de avaliação. Sem avaliação, torna-se impossível emitir qualquer juízo sobre o alcance dos propósitos, ficando comprometida a tomada de medidas corretivas. Concluímos que Qualidade, Melhoria e Avaliação são conceitos intrinsecamente interligados. Aliás, Dias e Melão (2009) afirmam "hoje em dia é indiscutível que a melhoria da qualidade pressupõe a avaliação dos sistemas educativos" (p.195).

Por outro lado, avaliar a Qualidade da Educação, numa lógica de centralidade no estabelecimento, só faz sentido se estiver associado um processo efetivo de autonomia e descentralização (Thélot, 2005; Costa, 2007). A autonomia das escolas consubstancia-se necessariamente em projetos educativos próprios e únicos. Então, acrescentamos nós que autonomia da escola, projeto educativo e avaliação de escolas constituem, por sua vez, uma trilogia de conceitos intrinsecamente ligados e indissociáveis (Rocha, 1999; Barroso, 2004; Azevedo, 2007; Costa, 2007).

O diploma que regula atualmente a gestão das escolas (Decreto-Lei n. ${ }^{\circ}$ $75 / 2008$ de 22 de abril), justifica a alteração legislativa com a obrigatoriedade de o Estado garantir "condições de qualidade e equidade, da forma mais eficaz e eficiente possível". O diploma assenta em dois pilares:

- "o reforço da participação das famílias e da comunidade na direção estratégica dos estabelecimentos de ensino";

- "o favorecimento da constituição de lideranças fortes" (prólogo do decreto). 
O reforço da autonomia das escolas é apresentado como instrumento necessário à realização da missão da escola. Registamos a prudência do legislador, evidenciada pela imposição de mecanismos de controlo ou regulação (e.g., participação da comunidade escolar no Conselho Geral, eleição do diretor, obrigatoriedade de prestação de contas).

Contudo, a responsabilidade pela Qualidade da Educação, prestada nas escolas, não pode recair exclusivamente nelas. Que lugar para a comunidade educativa em geral? E para a Administração Educativa?

\subsection{Qualidade educativa e avaliação: uma responsabilidade partilhada}

A descentralização parece agora irreversível. Porém, impõem-se algumas cautelas. Pois, a transição para a autonomia das escolas não pode ser feita sem a garantia da equidade no acesso a uma educação de qualidade, para todos e para cada um. Por outro lado, a Escola não pode escapar à lógica de responsabilização, transparência, racionalização da gestão e prestação de contas (accountability) que abrange a generalidade dos serviços públicos. A responsabilidade acrescida para a Escola, resultante de uma maior autonomia, a pressão externa da Administração e da comunidade educativa, em geral, a "crise de confiança na escola" e as solicitações talvez excessivamente ambiciosas que lhe são colocadas são, em conjunto, alguns dos fatores que têm dado força à necessidade de avaliação das escolas (Azevedo, 2007). Alaiz et al. (2003) associam-lhe numa certa desconfiança social e política.

O objetivo da melhoria é essencial. Mas, também nos parece claro que a autonomia pode ser interpretada como uma forma subtil de o Estado aliviar o peso da sua responsabilidade no desempenho do sistema, ainda que o mesmo Estado se aplique em garantir os referidos mecanismos de prestação de contas. O Estado terá então de encontrar formas para conviver com este dualismo (descentralização e autonomia das escolas vs. centralização e controlo do sistema) e estabelecer o ponto de equilíbrio entre a confiança que deposita nas escolas e o controlo que deve exercer nelas.

Em suma, pensamos que não se pode ambicionar qualquer processo de melhoria da Qualidade Educativa sem que lhe esteja associado um processo de avaliação. As responsabilidades tendem a recair nas escolas, focalizando-se também, mais recentemente, no desempenho docente e na avaliação interna e externa das escolas. 


\section{CONSIDERAÇÕES FINAIS}

$\mathrm{Na}$ reta final da nossa reflexão, a nossa primeira conclusão é no sentido de podermos afirmar, com toda a convicção, que não há uma definição única e universal para o conceito de Qualidade Educativa. Qualquer sentido que lhe seja atribuído é, por isso mesmo, parcial e subjetivo, dependendo do prisma através do qual se analisa a questão. Para cernar as suas significações, procurámos desocultar fatores que interagem entre si e recolher abordagens, de modo a ficarmos com uma ideia globalizante, conforme acabámos de expor. 
Figura 4

Modelo conceptual da representação do Conceito de Qualidade em Educação (elaboração própria)

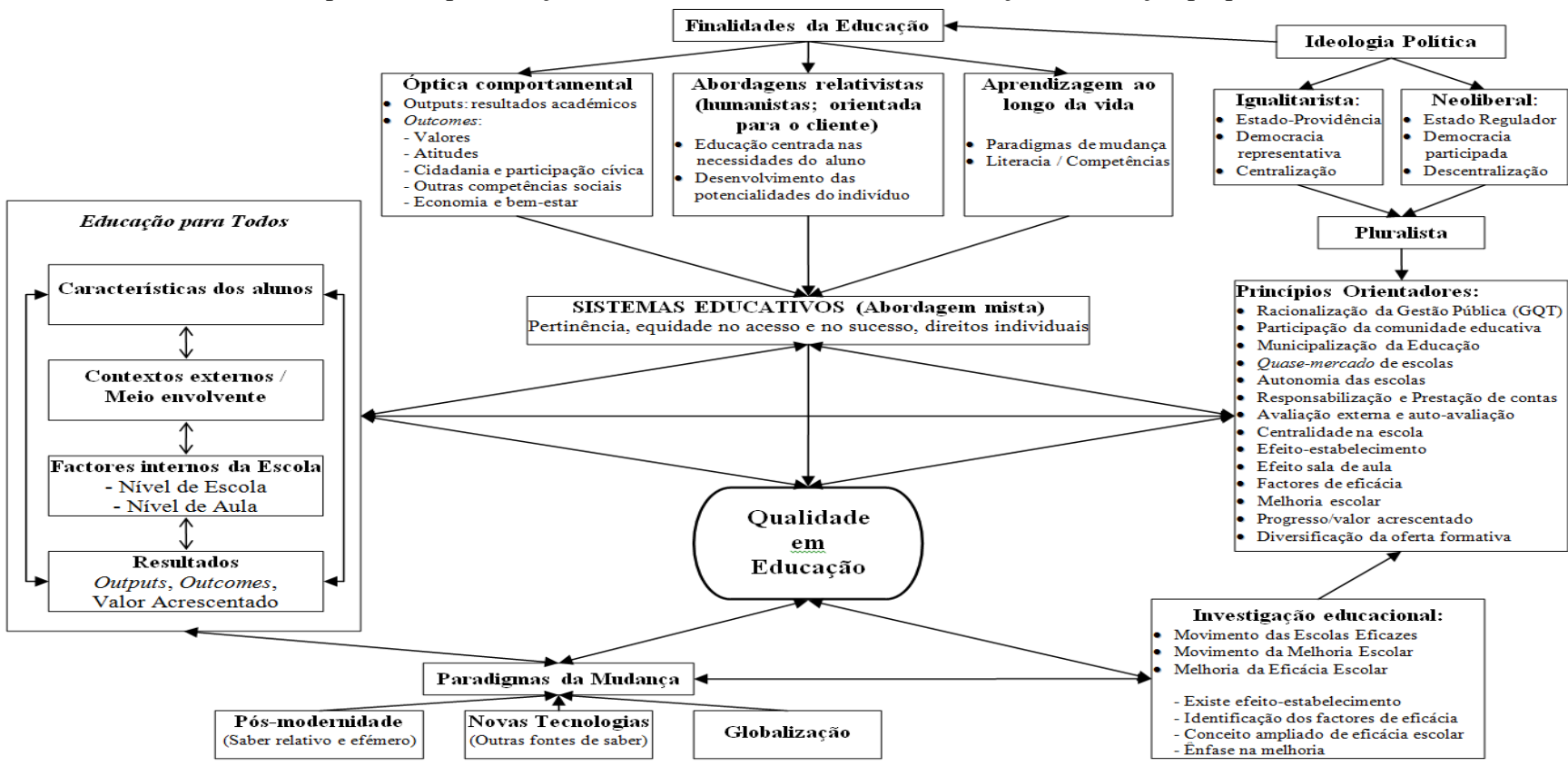


Adquirimos também a convicção de que um sistema educativo que permite que alguns alunos (muitos) fiquem de fora e não adquiram as competências essenciais para a vida, não pode, do nosso ponto de vista, proporcionar uma educação de qualidade. Referimo-nos ao conceito de Educação para Todos ou Escola Inclusiva, em sentido lato. A Educação, para ter qualidade, deve responder a todos, de modo diferente e adequado a cada um, mas pensar em todos.

Contudo, não nos parece exequível conceber um sistema educativo sem metas explícitas, cognitivas e não cognitivas. Perante a dinâmica de mudança que caracteriza o início do séc. XXI, a noção de competências e a aquisição da capacidade de aprender ao longo da vida assumem, por outro lado, uma importância crucial nos objetivos educacionais.

As políticas educativas traduzem ideologias. Estas, por sua vez, não têm ficado imunes à pressão das comparações com o contexto internacional, nem à influência da investigação educacional.

Propomos na Figura 4 um modelo teórico conceptual da representação do conceito de Qualidade Educativa, idealizado na sequência da revisão de literatura que efetuámos.

O conceito de Qualidade em Educação é a resultante deste enquadramento multidimensional. Com a presente reflexão, esperamos ter contribuído para uma hermenêutica do conceito, na expectativa de que outros possam vir a enriquecer o debate, de modo a procurarmos soluções para a melhoria. 


\section{REFERÊNCIAS}

AFONSO, A. (1998). Políticas Educativas e Avaliação Educacional. Para uma análise Sociológica da Reforma Educativa em Portugal (1985-1995). Braga: Universidade do Minho.

ALAIZ, V., GÓIS, E. \& GONÇALVES, C. (2003). Auto-avaliação de Escolas. Pensar e Praticar. Porto: Edições ASA.

ANKOMAH, Y. , KOOMSON J., BOSU, R. \& ODURO, G. (2005). A Review on the Concept of Quality Education. Perspectives from Ghana. EdQual Working Paper, 04. http://www.edqual.org/edqual/publications/ edqualworkingpaperquality4.pdf

AZEVEDO, J. (2007). Avaliação das Escolas: Fundamentar Modelos e Operacionalizar Processos. In Seminários e Colóquios. Avaliação das Escolas. Modelos e Processos (pp. 13-99). Lisboa: Conselho Nacional de Educação - Ministério da Educação.

BARRETT, A., CHAWLA-DUGGAN, R., LOWE, N. \& UKPO, E. (2006). The Concept of Quality in Education. A review of the 'international' literature on the concept of quality in education. EdQual Working Paper, 02. http://www.edqual.org/publications/workingpaperquality02.pdf

BARROSO, J. (2004). A Autonomia das Escolas: uma ficção necessária. Revista Portuguesa de Educação, 17 (2), 49-83.

BOLÍVAR, A. (2003) Como Melhorar as Escolas. Estratégias e dinâmicas de melhoria das práticas educativas. Porto: Edições ASA.

CARAPETO, C. \& FONSECA, F. (2006). Administração Pública. Modernização, Qualidade e Inovação (2a edição). Lisboa: Edições Sílabo.

CARNEIRO, R. (2004). A Qualidade da Educação, as reformas educativas e os professores. In A Educação Primeiro. Roberto Carneiro entrevistado por Joaquim Azevedo (pp. 113-127). Vila Nova de Gaia: Fundação Manuel Leão.

CASTILLO, J. (2004). Los Escenarios de la Educación: espacios formales, no formales, informales. In Andrés M. (Ed.), Teorías e Instituciones Contemporáneas de Educación (pp. 109-130). Madrid: Biblioteca Nueva.

COLEMAN, J., Campbell, E., Hobson, C., McPartland, J., Mood, A., Weinfeld, F. \& York, R. (1966). Equality of Educational Opportunity. Washington, D.C.: Government Printing Office.

COSTA, J. (2003). Imagens Organizacionais da Escola. Porto: Edições ASA. 
COSTA, J. (2007). Avaliação, Ritualização e Melhoria das Escolas: À procura da Roupa do Rei... In Seminários e Colóquios. Avaliação das Escolas. Modelos e Processos (pp. 229-236). Lisboa: Conselho Nacional de Educação - Ministério da Educação.

DIAS, N. \& MELÃO, N. (2009). Avaliação e Qualidade: Dois Conceitos Indissociáveis na Gestão Escolar. Téckne, 7 (12), 193-214.

DIAZ, A. (2003). Avaliação da Qualidade das Escolas. Porto: Edições ASA.

ESTEBAN, M. (2008). Silenciar a Polissemia e Invisibilizar os Sujeitos: Indagações ao Discurso sobre a Qualidade da Educação. Revista Portuguesa de Educação, 21 (1), 5-31.

EURYDICE (2007a). Autonomia das Escolas na Europa. Políticas e Medidas. http://eurydice.gepe.min-edu.pt

EURYDICE (2007b). O Sistema Educativo em Portugal - 2006/2007. http://www3.uma.pt/nunosilvafraga/wp-content/uploads/2007/07/ eurydice-o-sistema-educativo-em-portugal2006-2007.pdf

HANUSHEK, E. (2005). Why Quality Matters in Education. Finance \& Development, 42 (2).

LIBÓRIO, H. (2004). A Avaliação das Escolas. Desenvolvimento Organizacional e Ritualização. Tese de Mestrado em Análise Social e Administração da Educação, área de especialização em Administração da Educação. Aveiro: Universidade de Aveiro.

LIMA, J. (2008). Em Busca da Boa Escola. Instituições Eficazes e Sucesso Educativo. V. Nova de Gaia: Fundação Manuel Leão.

MARCHESI, A. \& MARTÍN, E. (1998). Calidad de la Enseñanza en Tiempo de Cambio. Madrid: Alianza Editorial.

MORGADO, J. (2004). Qualidade em Educação. Um Desafio para os Professores. Barcarena: Editorial Presença.

OCDE (1992). As Escolas e a Qualidade. Rio Tinto: Edições ASA.

OCDE (2008a). Quality Education for All: Much More than a Financial Challenge. Remarks by Angel Gurría, OECD Secretary-General, during the presentation of Education at a Glance 2008. http://www.oecd.org/

document/2/0,3343,en_2649_34487_41280002_1_1_1_1,00\&\&enUSS_01DBC.html

OCDE (2008b). Regards sur l'éducation 2008. Les indicateurs de l'OCDE. http://www.oecd.org/dataoecd/23/24/41284079.pdf

OCDE (2009a). The Return to Investment in Education. Remarks by Angel Gurría, OECD Secretary-General, for the launch of Education at a Glance 2009. http://www.oecd.org/document/43/0,3343,en_2649_ 37455_43662571_1_1_1_1,00.html 
OCDE (2009b). Education at Glance. OECD Indicators. http://www.oecd.org/dataoecd/41/25/43636332.pdf

OCDE (2009c). Panorama sobre a Educação: Indicadores da OCDE. http://www.oecd.org/dataoecd/1/4243658785.pdf

PACHECO, J. (2007). Currículo, Investigação e Mudança. In $A$ Educação em Portugal (1998-2006). Alguns contributos de investigação, (pp. 80-148). Lisboa: Conselho Nacional de Educação/ Ministério da Educação.

ROCHA, A. (1999). Avaliação de Escolas. Porto: Edições ASA.

SCHEERENS, J. (2004). Melhorar a Eficácia das Escolas. Porto: Edições ASA.

THÉLOT, C. (2005). L'évaluation dans le Système Éducatif. Comunicação apresentada no $18^{\circ}$ Colóquio da ADMEE (Association pour le Développement des Méthodologies d'Évaluation en Education). http://www.pedagopsy.eu/claude_thelot.htm

UNESCO (2000). The Dakar Framework for Action. Education For All: Meeting Our Collective Commitments. http://unesdoc.unesco.org/images/ 0012/001202/120240e.pdf

UNESCO (2004). EFA Global Monitoring Report 2005. Education for All. The Quality Imperative. http://unesdoc.unesco.org/images/0013/001373/ 137333e.pdf 